\title{
IoT Based Smart Public Distribution System
}

\author{
R. Sureshkumar, S. Arunadevi
}

\begin{abstract}
This project proposes an automatic strategy for conveyance of products to the individual card holders. The database has subtleties of commodities distribution to individual card holders. By utilizing the android phone, the clients get to their database and they can see the stock availability. The Minutiae extraction based fingerprint matching algorithm is used for identification of individual cardholders. For automatic distribution of commodities, the DC Motors are used. The Raspberry pi controller is used to control the DC Motor and to open and close the valves.
\end{abstract}

Key words: Public distribution system, smart phone, Finger print module, Automatic ration distributing equipment.

\section{INTRODUCTION}

The Indian government provides food items at lower rates to individuals through ration shops. But it is not properly distributed to cardholders because of malpractices. To overcome this drawback the system has designed with following advantages;

1.Predefined data about the measure of apportion to be passed on.

2.Unique fingerprint reorganization system to identify the customer.

3. Automated Ration distributing Equipment.

The motivation of this project is to make a helpful framework to ensure the Interests of individuals in general by countering the mischievous activities [2]. The primary inspiration of this structure is to realize unique finger print matching algorithm for confirmation of the customer and to reduce malpractices. In the Public distribution system (PDS), the central government supplies basic items at sensible expense.

Against the basic wares act there are various malpractices going on in ration shops. People are forced to wait in long lines to purchase the essential things. At present Card holders and their relatives subtleties are secured in a book.
Revised Manuscript Received on 14 August, 2019.

R.Sureshkumar, Assistant professor, EEE department, Kumaraguru College of Technology, Tamil Nadu, Coimbatore, Tamilnadu, India.(Email: sureshkumar.r.eee @kct.ac.in)

S.Arunadevi, Assistant Professor, S\&H Department, Kumaraguru College of Technology, Coimbatore,Tamil Nadu, India.(Email: arunadevi.s.sci@kct.ac.in).

\section{SYSTEM OVERVIEW}

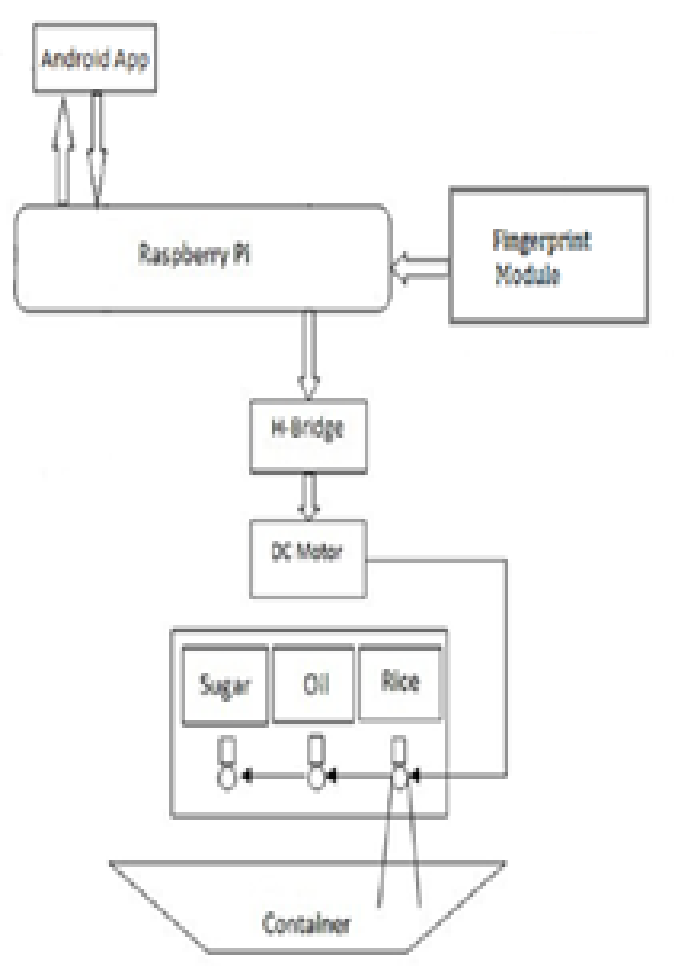

Fig 1. Block diagram

\section{III.HARDWARE TOOLS}

1. Finger print module: A unique finger print module is interfaced with the Raspberry-pi. A Minutiae algorithm is utilized to process the unique finger print impression procured from the module. The unique finger print identification incorporates two areas: Fingerprint enrollment and unique finger print matching.

2. Raspberri pi: The individual cardholder details are stored in database. Once the controller identifies the thumb print, Raspberry pi takes the consecutive number from peruser and access relating record.

To automatically distribute the sugar, rice and oil, three DC Motors are utilized to control the valve arrangement. The hydraulic valve is used to control the stream rate. 
IOT BASED SMART PUBLIC DISTRIBUTION SYSTEM

\section{SYSTEM SOFTWARE}

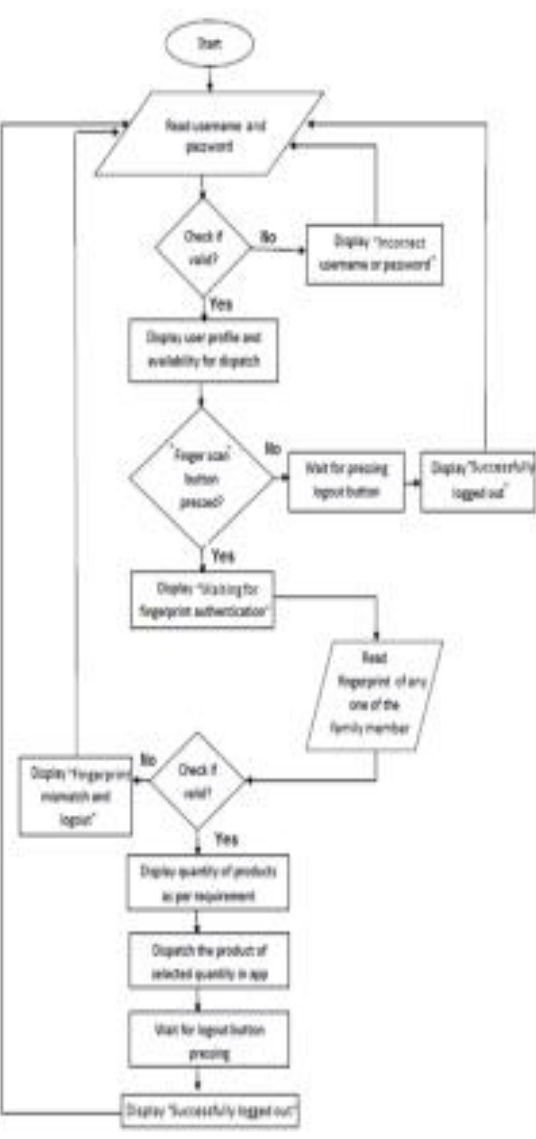

Fig 2 .Flowchart

\section{ALGORITHM}

Given the test Fingerprint Image the objectives are,

1. Pre-processing the test Fingerprint.

2. Extract the minutiae points.

3. Matching test Fingerprint with the database.

\section{Minutiae based finger print algorithm:}

Input: Gray scale finger print image

Output: Verified finger print image with matching score.

1. Finger print is binarized

2. Thinning on binarized picture.

3. Minutiae points are extracted. Data matrix is generated to get the position, orientation and type of Minutiae.

4. Matching of the test fingerprint with template.

5. Matching score of the two images is processed.

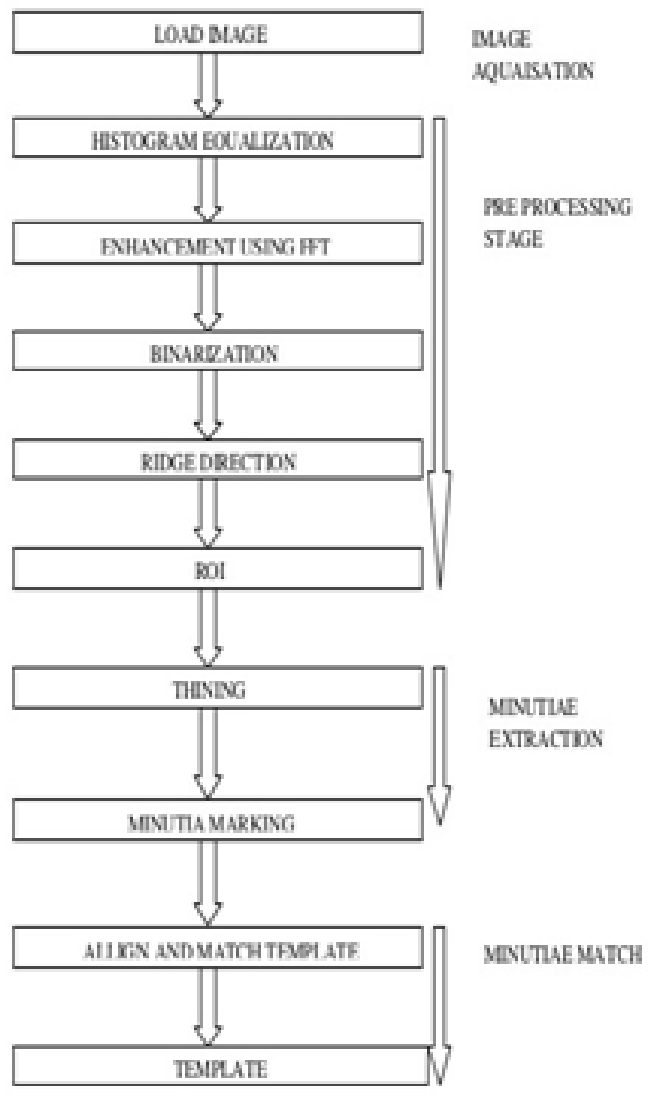

Fig 3. Flowchart of minutiae based matching

Before purchasing the customer needs to give their unique fingerprint mark to withdraw the things. First the customer fingerprint impression is compared with existing database to identify the customer. Later customer can buy the wares if unique finger print is coordinated. Fig 3.shows the flowchart of minutiae based matching algorithm.

\section{RESULTS}

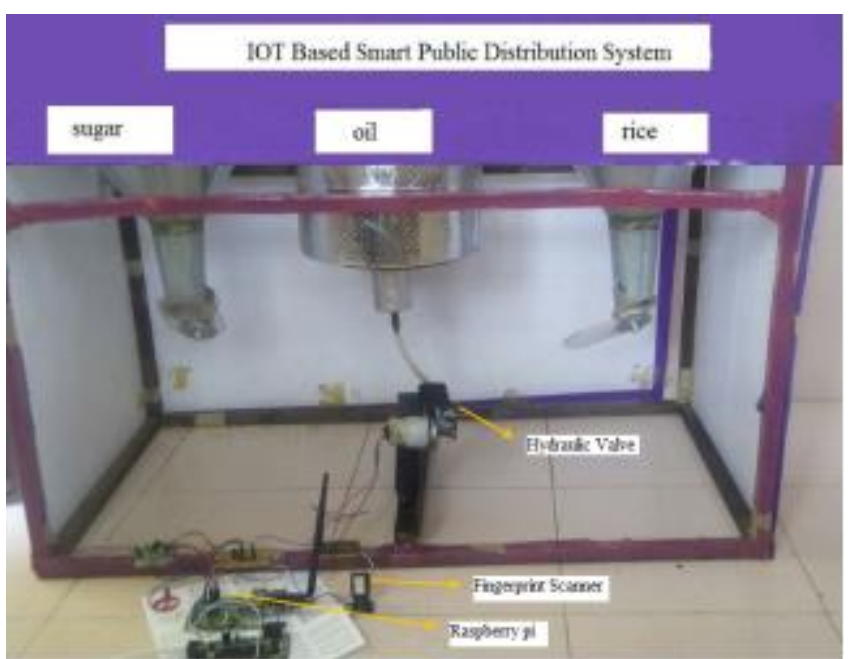

Fig 4. Snapshot showing the dispensing containers

Fig 4 demonstrates the smart public distribution system.

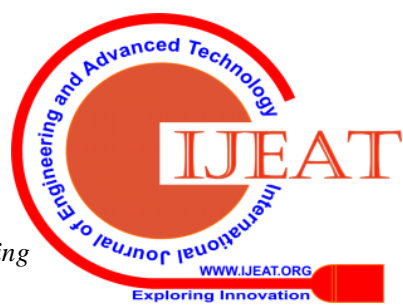




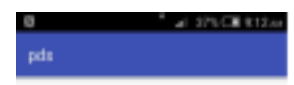

Enroll
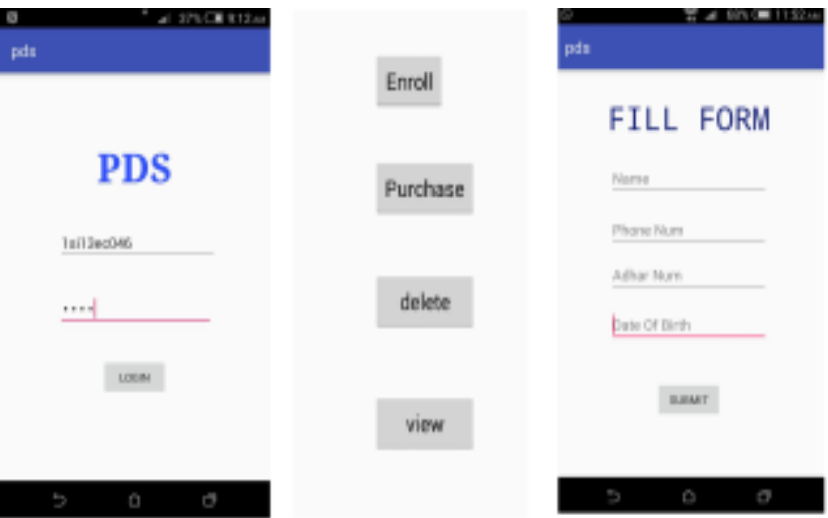

(a)

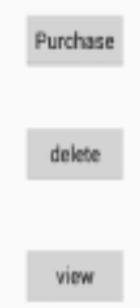

FILL FORM

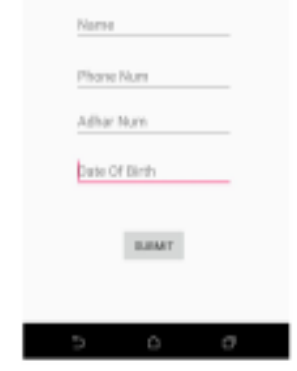

(b)

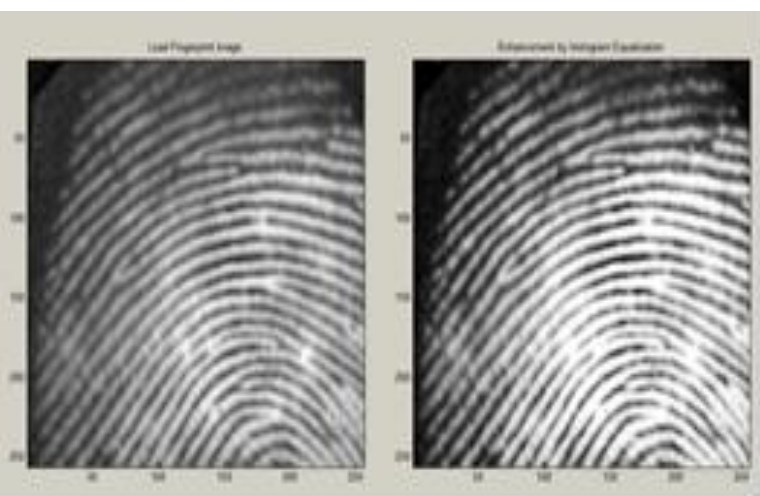

Fig 9 Matlab results on fingerprint matching

\section{CONCLUSION}

This automatic ration distributing system replaces the existing fair ration shops. It will assist the nation's economy with achieving new statues. The electronic PDS puts less human work. The data are put away in database, so misbehaviors can be avoided. It will be extremely useful to the public.

\section{REFERENCES}

1. Sana A, Qader P, Dube R, Smart Card based e-Public Distribution System , Inter-national Journal of Advanced Research in Computer and Communication Engineering,Vol. 5, Issue 5, May 2016.

2. Ashok Kumar D, Ummal Sariba B, A Comparative Study on Fingerprint Matching Algorithms for EVM, Journal of Computer Sciences and Applications, Vol. 1, No. 4,pp:55-60,2013.
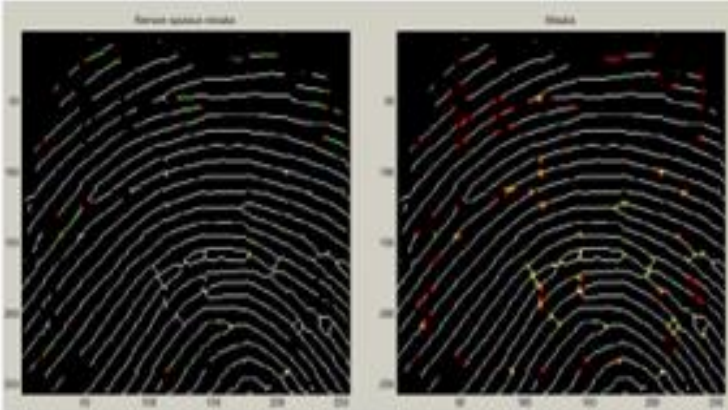

Fig 8. Figure showing the extraction of minutiae points

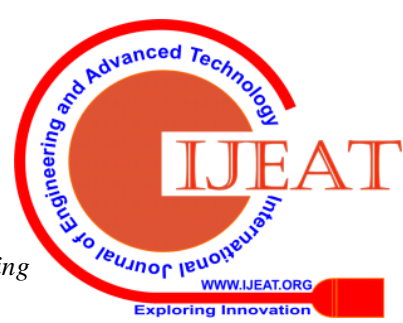

